\title{
Methodological approaches for the efficient production of parapharmaceuticals based on wild raw materials
}

\author{
G.H. Gumerova ${ }^{1, *}, M . R$. Vakhitov $^{1}$, and I.S. Dokuchaeva ${ }^{1}$ \\ ${ }^{1}$ Kazan National Research Technological University, Republic of Tatarstan, Russian Federation
}

\begin{abstract}
The foundations of efficient production are laid at the stage of developing a high-tech product. The object of research is wild berries (lingonberry, honeysuckle, viburnum, cranberry, cloudberry, sea buckthorn, mountain ash, aronia), which are used as a source of a natural complex of biologically active substances and trace elements as the main substance of a new parapharmaceutical. The primary technological task of food engineering of paramarceuticals is the maximum extraction of biologically active substances of plant raw materials and their preservation in their native form during the warranty period of storage. Therefore, as the main criterion for changing the properties of raw materials during processing, we used the amount of change in the redox potential of the system. A set of methodological approaches has been developed to ensure the quality and safety of the new parapharmaceutical.
\end{abstract}

\section{Introduction}

Parapharmaceuticals are biologically active substances that are intended to maintain the functional state of the human body, to prevent diseases and adapt to adverse environmental factors. This product is not medicine for treatment any diseases. In recent years, multicomponent parapharmaceutical products based on wild plants have been in great demand all over the world.

Food Engineering of new parapharmaceutical products lays the foundations for efficient production and lifecycle in the development phase of such products. Liquid parapharmaceuticals have a whole range of properties attractive for the consumer. These properties include high bioavailability and ease of use in comparison with tableted and encapsulated forms.

Parapharmaceutical products based on wild berries are of particular value, since they are superior to cultivars in content of many biologically active substances and nutritional value. As an additional attraction for consumers, wild berries, unlike cultivated ones, are not treated with chemicals during the growth period.

Lingonberries and cranberries are widely used in traditional medicine as an antipyretic, diuretic, stimulant and tonic, also to prevent colds and increase immunity $[1,2]$. Various wild berries have been investigated in field bioassays and then in laboratory studies and have been shown to be capable of dose-dependent inhibition of pro-inflammatory cytokines that are associated with metabolic syndrome and inhibit aldose reductase, an enzyme associated with diabetic retinopathy [3]. The antioxidant capacity and level of quercetin in wild berries of Alaska were studied [4], as well as the antioxidant and antimicrobial activity of polyphenolic extracts of wild berries growing in the South-east of Serbia [6]. The authors [7] found and quantified more than 50 different flavonols in berries and fruits and proved that wild berries significantly exceed cultivated crops in the content of total flavonols. The authors [8] investigated the nutraceutical properties of wild berries from Southern Italy. Articles [9-16] are devoted to the study of various aspects of the chemical composition and use of wild berries.

Currently, tinctures, syrups, extracts and powders, biologically active additives, medical cosmetics, as well as pharmacological preparations are produced and actively sold on the basis of wild plants. The market for parapharmaceutical products has been developing intensively in recent years and is in good demand among consumers, because such products are available without a prescription and are useful to a wide range of the population.

In recent years, the task of maintaining health, working capacity and prolonging active longevity has become most relevant in Russia, so the problem of substantiating methodological approaches for creating such products is of particular importance.

Wild berries are a source of a number of micronutrients - polyphenolic compounds, vitamins, organic acids, macro - and microelements. Therefore, at the first stage of development of the formulation of parapharmaceutical products, the compatibility of the ingredients and the need for minimal impact on the complex of biologically active substances in the process of technological processing are taken into account.

\footnotetext{
* Corresponding author: ggx70@yandex.ru
} 


\section{Subjects and methods of research}

The subject of the study was wild fruits and berries growing on the territory of the Russian Federation: cranberries, lingonberries, honeysuckle, viburnum, cloudberry, sea buckthorn, ashberry and aronia. For experimental studies, freshly frozen berries were used. The berries were thawed at room temperature and subjected to research and processing. The analysis of the qualitative indicators of berries was carried out according to the generally accepted method for the incoming control of plant raw materials in the food industry.

The content of soluble solids (extract) in the fruit and berry raw materials was determined by the method of digestion with the subsequent determination of the extract content by the refractometric method. The content of vitamin $\mathrm{C}$ was determined by the iodometric method. To determine the $\mathrm{pH}$ and redox potential (ORP) of juices and extracts, an inoLab 7110 liquid analyzer (Germany) was used.

The values of the physico-chemical parameters of the samples were obtained from at least three readings of the device for each of three parallel experiments. The studies were carried out in a university laboratory of the Department «Food Production Equipment» of the Kazan National Research Technological University.

\section{Results and discussion}

In constructing a generalized methodology for creating an innovative parapharmaceutical, we used a systematic method that considers in interrelation all the objects and procedures used. The consideration of objects as complex systems as the main procedure of system analysis involves the initial dismemberment and detailing in the description of the properties and specifics of the raw materials, ingredients and technologies used.

The next stage is to study the interaction of the components used in order to exclude undesirable products of their interaction. Sometimes, on the contrary, it is important to investigate, prove and justify the use of the synergy of the individual components of the formulation, the applied effects aimed at activating the overall effect of the parapharmaceutical, as well as stabilizing its properties during the guaranteed shelf life

The final stage of development is generalization, where the decisive factors that determine the quality of the finished product are highlighted and substantiated. This approach demonstrates an iterative formulation development model and technology of an innovative product (Fig. 1).

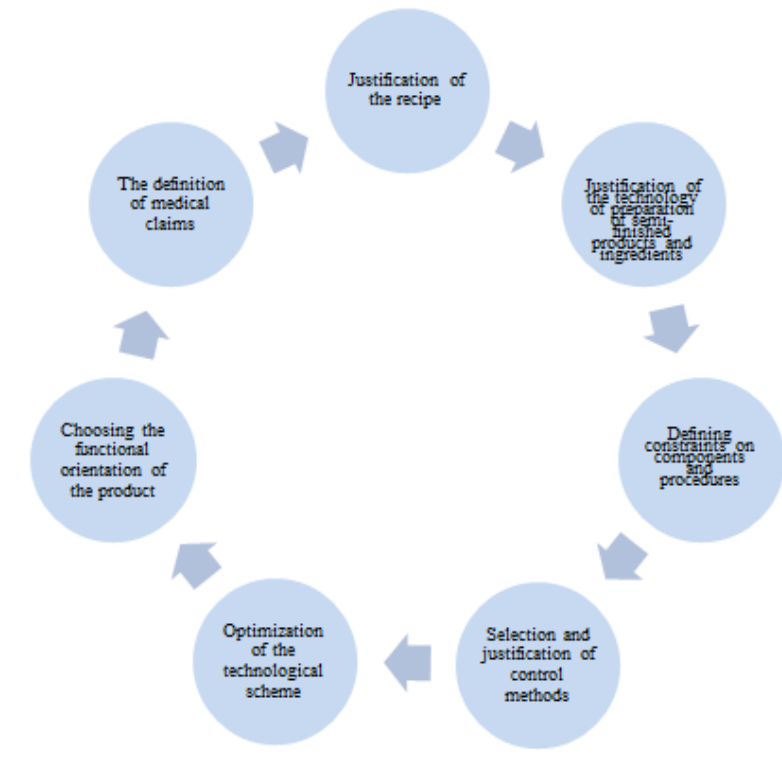

Fig. 1. Iterative formulation development model and parapharmaceutical technology.

The use of an iterative model is an important tool for customer feedback, meeting market needs and ensuring the high quality of a new product. Wild berries (sea buckthorn, lingonberry, honeysuckle, viburnum, cranberry, ashberry, cloudberry, aronia) are the most valuable renewable plant resource due to the content of a whole complex of biologically active substances (macronutrients, sugars, organic acids, tannins, P-active flavonoids, ascorbic acid and other vitamins). They have long been used by people for consumption both fresh and processed into medicinal products for long-term storage (juices, extracts, purees, jams, syrups).

The rich chemical composition of wild berries involves not only their traditional processing, but also complex processing, including the additional use of biologically active substances (micronutrients) of solvent cake and pulp.

The fundamental principle of the development of high - performance parapharmaceuticals is high-quality raw materials. Plant raw materials used for the production of parapharmaceutical products must comply with the requirements for the safety of food products and ingredients for food industry based on the HACCP principles, as well as be subjected to all stages of incoming control in accordance with the requirements of the state Pharmacopoeia of the Russian Federation.

The results of the incoming control of raw materials for the solids content and vitamin $\mathrm{C}$ are shown in Table 1. 
Table 1. The solids content (extract) and vitamin $\mathrm{C}$ in wild berries.

\begin{tabular}{|c|c|c|}
\hline Raw material & $\begin{array}{c}\text { Mass fraction of } \\
\text { soluble solids, \% }\end{array}$ & $\begin{array}{c}\text { Vitamin C } \\
\text { content (mg } \\
\text { per 100 g of } \\
\text { raw weight) }\end{array}$ \\
\hline Lingonberry & 15.3 & 24.2 \\
\hline Honeysuckle & 16.1 & 146.4 \\
\hline Kalina & 13.0 & 79.8 \\
\hline Cranberries & 11.7 & 33.5 \\
\hline Cloudberry & 8.0 & 29.4 \\
\hline Sea-buckthorn & 17.3 & 200.4 \\
\hline Ashberry & 12.0 & 70.6 \\
\hline Aronia & 19.5 & 15.6 \\
\hline
\end{tabular}

The vast majority of components of plant raw materials in the composition of parapharmaceuticals, which determine their technological and consumer properties (aroma, taste, transparency), as well as biological activity, are in a colloidal state. They have a complex chemical composition, which may be different for one type of raw material, depending on the growing and climatic conditions. Individual substances of protein, phenolic, carbohydrate nature and their mixed complexes can often cause turbidity of products made on the basis of plant raw materials. The processes occurring at the interface of colloidal particles determine the stability of the colloidal system of parapharmaceuticals during long-term storage.

Soluble polysaccharides often cause turbidity of colloidal systems during storage. They are present in plants in the form of insoluble protopectin (a compound of methoxylated polygalacturonic acid with galactan and araban), as well as soluble pectin.

Various methods of influencing on plant materials were considered in order to preserve their quality and biologically active properties for a long time. The preferred processing methods are those that gently affect the colloidal complex of each individual type of wild plants and, after blending, the entire colloidal system as a whole. Ultra-jet blending of plant components and pulsation extraction technology are considered to be the most optimal in terms of meeting requirements described above.

Figure 2 is a diagram showing changes in $\mathrm{pH}$ and redox potential of the system of individual parapharmaceutical components as a result of technological processing with ultra-jet homogenization.

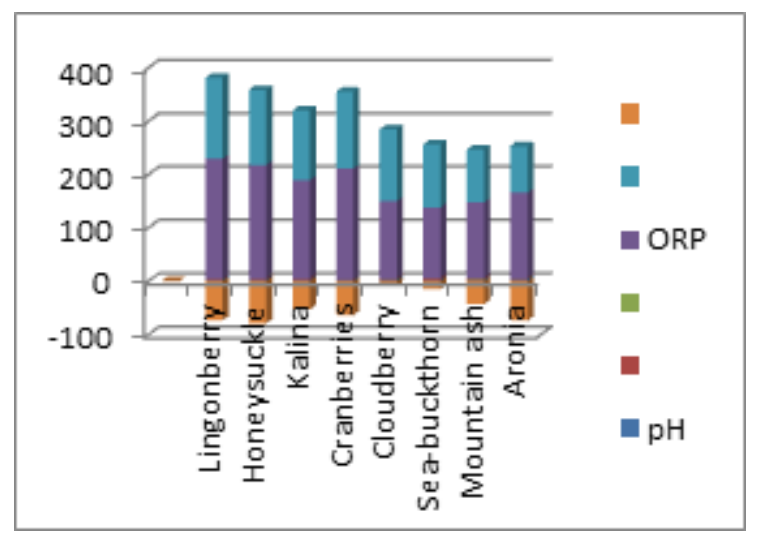

Fig. 2. Changes in the $\mathrm{pH}$ and ORP of parapharmaceutical ingredients during processing.

Figure 2 shows that the change in $\mathrm{pH}$ in plant raw materials during processing occurs in a wide range of $0.82-13.86 \%$. We can see an increase in $\mathrm{pH}$ in honeysuckle, sea buckthorn, mountain ash and aronia and decrease in cranberries, viburnum, cranberries and cloudberries. The largest deviation from the initial value $(13.86 \%)$ occurs in cloudberry, the smallest $(0.82 \%)$ in honeysuckle. Changes in redox potential are observed in the range of $6.25-45.62 \%$ with a maximum decrease in aronia $(45.62 \%)$ and a minimum $(6.25 \%)$ in cloudberry.

In view of the above, the basic technological scheme for the preparation of a new parapharmaceutical should include the following technological stages (Fig 3).

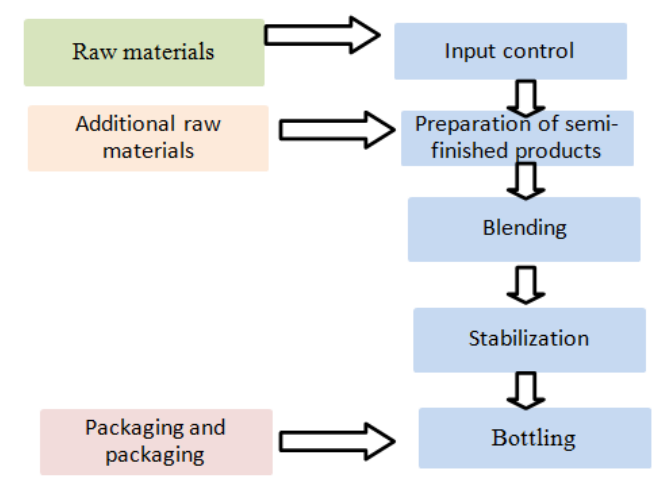

Fig. 3. Basic technological scheme of preparation of a parapharmaceutical product.

In development of a new product, it is also necessary to take into account a number of factors that can cause a possible threat to the safety of utilization of product by consumers, as well as hazards that can affect the stability and quality of the product itself. Such factors include hazards of chemical, physical, microbiological and technological origin (Table 2.) 
Table 2. Classification of hazardous factors in the production of parapharmaceutical products.

\begin{tabular}{|c|c|}
\hline Danger & Basic elements \\
\hline Chemical & Toxic substances, allergens \\
\hline Physical & $\begin{array}{c}\text { Mechanical impurities or other } \\
\text { inclusions that unintentionally } \\
\text { get into the product during the } \\
\text { destruction of glass containers, } \\
\text { brittle materials of equipment } \\
\text { and auxiliary materials }\end{array}$ \\
\hline Biological properties & Pathogenic microorganisms \\
\hline Technological \\
solutions & $\begin{array}{c}\text { Chemical composition of raw } \\
\text { materials, semi-finished } \\
\text { ingredients }\end{array}$ \\
\hline
\end{tabular}

A preliminary analysis of these factors is a necessary component of the system to ensure the stable quality of the developed product throughout the entire life cycle.

\section{Conclusion}

The development of methodological approaches to the development of the formulation and technology of new parapharmaceutical products is based on the use of a systematic approach, which implies the study of subjects (raw materials, methods of control and exposure, technological techniques) as complex systems. The fundamental principle of our methodology is the requirement of safety of the finished product, the ingredients and technologies used, and ensuring efficient production.

Production efficiency directly depends on the quality of elaboration and execution at all stages of development, production and market launch of an innovative product. Feedback from consumers and meeting market needs are the most important components of a successful launch of an innovative product.

\section{References}

1. K. Mäkinen Kauko, E. Söderllng, A quantitative study of mannitol, sorbitol, xylitol, and xylose in wild berries and commercial fruits, Journal of food science, 45 (2), 367-371 (1980)

2. L. Nilova, S. Malyutenkova, R. Ikramov, A study of the chemical composition and antioxidant properties of products of wild berries processing, IOP Conference Series: Earth and Environmental Science, 337, 012025 (2019)

3. M.A. Lila, J. Kellogg, M.H. Grace, G.G. Yousef, T.B. Kraft, R.B. Rogers, Stressed for success: how the berry's wild origins result in multifaceted health protections. Acta Horticulturae, Proc. Tenth Int. Symp. on Vaccinium and Other Superfruits, 1017, 23-43 (2014)

4. R.H. Leiner, P.S. Holloway, D.B. Neal, Antioxidant Capacity and Quercetin Levels in Alaska Wild Berries, International Journal of Fruit Science, 6 (1), 83-91 (2006)
5. B.C. Radovanović, S.M. Anđelković, A.B. Radovanović, M.Z. Anđelković, Antioxidant and Antimicrobial Activity of Polyphenol Extracts from Wild Berry Fruits Grown in Southeast Serbia, Tropical Journal of Pharmaceutical Research, 12 (5) (2013)

6. Francisc Vasile Dulf, Andrei Sanda, Andrea Bunea, Carmen Socaciu, Fatty acid and phytosterol contents of some Romanian wild and cultivated berry pomaces, Chemical Papers, 66 (10), 925-934 (2012)

7. Maja Mikulic-Petkovsek, Ana Slatnar, Franci Stampar, Robert Veberic, HPLC - MSn identification and quantification of flavonol glycosides in 28 wild and cultivated berry species, Food Chemistry, 135 (4), (2012)

8. Marisa Carmela Caruso, Fernanda Galgano, Roberta Tolve, Maria Pecora, Idolo Tedesco, Fabio Favati, Nicola Condelli, Nutraceutical properties of wild berry fruits from Southern Italy, Journal of Berry Research, 6 (3), 321-332 (2016)

9. F.D. Covaciu, D.A. Magdas, A. Dehelean, I.C. Feher, S. Radu, Elemental, Isotopic, and Pesticide Analysis of Wild and Cultivated Berries, Analytical Letters, (2017) DOI: 10.1080/00032719.2017.1299161

10. A.M. O'Sullivan, Y.C. O'Callaghan, T.P. O'Connor, N.M. O'Brien, Bioaccessibility of polyphenol and carotenoid from wild Irish berries subjected to an in vitro digestion procedure, Proceedings of the Nutrition Society, 70 (OCE3), E 61 (2011)

11. E. Bere, Wild berries: a good source of omega-3, European Journal of Clinical Nutrition, 61 (3), 431433 (2006)

12. S.C. Debnath, Germplasm characterization, propagation and maintenance of health-promoting wild berries and medicinal plant roseroot (Rhodiola Rosea L.), Acta Horticulturae, 1098, 61-69 (2015)

13. Ilia Rodushkin, Fredrik Ödman, Henning Holmström, Multi-element analysis of wild berries from northern Sweden by ICP techniques, The Science of the Total Environment, 231 (1), 53-65 (1999)

14. Robert Veberic, Ana Slatnar, Jan Bizjak, Franci Stampar, Maja Mikulic-Petkovsek, Anthocyanin composition of different wild and cultivated berry species, LWT - Food Science and Technology, 60 (1), 509-517 (2015)

15. Jari Miina, Timo Pukkala, Mikko Kurttila, Optimal multi-product management of stands producing timber and wild berries, European Journal of Forest Research, 135 (4), 781-794 (2016)

16. Z. Marjanovic-Balaban, S. Grujic, M. Jasic, D. Vujadinovic, Testing of chemical composition of wild berries, Third International Scientific Symposium «Agrosym 2012», Jahorina, Bosnia and Herzegovina, 15-17 November 2012, Book of Proceedings, 154-160 (2012) 